of cardiac death. That would be, as Bassan writes, the height of folly. Instead we recommended further evaluation of patients in whom monitoring performed for clinical reasons shows abnormal findings (described in our paper). As we wrote, the benefit of managing silent ischaemia in elderly people is unclear. Nevertheless, if silent ischaemia is diagnosed it is clinically and ethically accepted, even in elderly patients, that risk factors should be controlled and treatment with aspirin and even $\beta$ blockers considered. Specific treatment of the marker, arrhythmia, would be unwise and certainly ineffective. An important question is whether these markers are also valid in middle aged people.

Bassan argues that the markers were defined arbitrarily. This is not true. All clinically relevant arrhythmias shown by Holter monitoring were included in the analysis, and the cut off points for abnormal findings were based on the criteria used in other studies attempting to find prognostic markers.

Department of Geriatrics,

ISMO RÄIHÄ

University of Turku

SF-20700 Turku

Finland

1 Bassan M. Continuous ambulatory electrocardiography in elderly people. BMF 1995;310:468. (18 February.)

2 Räihä I, Piha J, Seppänen A, Puukka P, Sourander L. Predictive value of continuous ambulatory electrocardiographic monitoring in the elderly. $B M F$ 1994;309:1263-7. (12 November.)

\section{The persistent vegetative state}

\section{Task force's definition influences interpretation of outcome}

EDITOR,-Robin S Howard and David H Miller's comments on the study by the American MultiSociety Task Force on the persistent vegetative state leaves two aspects of the prognosis that need to be clarified. ${ }^{1}$ The adult mortality of $82 \%$ at three years and $95 \%$ at five years might suggest that more prolonged survival in a vegetative state is uncommon. Yet it is the prospect of long survival that promotes the debate about continuing treatment. The task force, however, defined a persistent vegetative state as being in a vegetative state at only one month after an acute cerebral insult; this would include some patients who had been vegetative for only a few days after a period in coma. Many such patients die in the next few months and some recover, leaving only $59 \%, 37 \%$, and $24 \%$ of those vegetative at one month still alive and vegetative at three, six, and 12 months. Death rates reported for patients vegetative at three months in $\mathrm{Japan}^{23}$ and at six months in the Netherlands ${ }^{4}$ were much lower, while the death rate for those still vegetative at one year is quite low but not yet accurately documented.

With regard to recovery, the proportion of head injured adults who recover consciousness after three months in a vegetative state but who are severely disabled is more than half, not one fifth as Howard and Miller state. ${ }^{1}$ Just how severely disabled they may be is evident from Andrews's report of 11 recoveries after four months or more in a vegetative state. ${ }^{5}$ Only four patients could speak, only four could feed themselves, and five still needed a gastrostomy.

BRYAN JENNETT Professor emeritus of neurosurgery Institute of Neurological Sciences, Southern General Hospital, Glasgow G51 4TF

1 Howard RS, Miller DH. The persistent vegetative state. $B M 9$ 1995;310:341-2. (11 February.)

2 Higashi K, Sakata M, Hatano M, Abiko S, Ihara K, Katayama S, et al. Epidemiology studies on patients with a persisten vegetative state. $\mathcal{F}$ Neurol Neurosurg Psychiatry 1977;40:876-85.
3 Higashi K, Hatano M, Abiko S, Ihara K, Katayama S, Wakuta $\mathrm{Y}$, et al. Five year follow-up study of the patients with , et al. Five year follow-up study of the patients with
persistent vegetative state. $\mathcal{f}$ Neurol Neurosurg Psychiatry persistent vegetat

4 Minderhoud JM, Braakman R. Het vegeterende bestaan. Ned Tijdschr Geneeskd 1985;129:2385-8.

5 Andrews K. Recovery of patients after four months or more in the persistent vegetative state. $B M \mathcal{F}$ 1993;306:1597-600.

\section{Report is unnecessarily negative}

EDrror,-Robin S Howard and David H Miller's editorial on the persistent vegetative state ${ }^{1}$ is timely because several working parties are debating this condition, including the Royal College of Physicians; the European Union's biomedical and health research programme (BIOMED I) at the Centre of Medical Law and Ethics at King' College, London; and an international working party and conference on management of the condition held at the Royal College of Physicians in March. The editorial reviews the position of the Multi-Society Task Force. ${ }^{23}$ Considerable concern has been expressed, particularly among consultants in rehabilitation, that the task force's report is unnecessarily negative.

The international working party was set up because of concern that insufficient attention was being given to the treatment, especially the rehabilitation, of patients in a persistent vegetative state. It will debate the concern about the terminology used; the classification of patients into various levels of persistent vegetative state and states of low awareness; the need for more sensitive measurement scales; the effectiveness of treatment programmes; and the relevance of rehabilitation for medical, legal, and social policy. Concern mus be expressed at the assumption made by many people that severe disability is not worth achieving. This has implications for the treatment not only of people with severe brain damage but also of those with other chronically disabling disorders.

The persistent vegetative state is so rare that it is difficult, even in specialist units such as the Persistent Vegetative State Rehabilitation Unit in Putney, to build up sufficient research data to provide answers to many of the questions required to make reasonable clinical, legal, and social decisions on behalf of such unfortunate patients and their families.

KEITH ANDREWS Royal Hospital and Home, Putney,

London SW15 3SW

1 Howard RS, Miller DH. The persistent vegetative state. $B M$ 1995;310:341-2. (11 February.)

2 Multi-Society Task Force on PVS. Medical aspects of persisten vegetative state (first part). N Engl F Med 1994;330:1499-508.

3 Multi-Society Task Force on PVS. Medical aspects of persisten vegetative state (second part). N Engl F Med 1994;330:1572-9.

\section{Eclampsia in the United Kingdom}

\section{More information is required}

EDrTor,-K A Douglas and C W G Redman have produced an invaluable 70 year landmark report on the state of eclampsia in the United Kingdom. Hopefully, more information will follow as some aspects are not discussed in detail in their paper.

What of the $138(26 \%)$ women who were not included in the survey, having originally seemed to fit the criteria? What did these women with pseudoeclampsia have? Five of the 64 who had a fit while receiving community based care had hypertension and albuminuria, but how many had one or the other and how many had been seen in the week preceding the fit? The 356 singleton pregnancies had a fetal loss of $84 / 1000$, but the 55 babies in the 27 multiple pregnancies survived. Was the eclampsia different in these two groups- for example, in the incidence of major maternal complications? Roughly a quarter of the patients were multiparous, which suggests that primiparous women are more susceptible to the condition. To what extent is the different incidence of eclampsia in teenagers accounted for by the effect of parity? What are the relative risks of eclampsia in primigravidas and multigravidas? Was there any information about the multigravidas-for example, did they have new partners?

We find it difficult to understand the results under the heading "antenatal care." If one follows the standard antenatal care described in the article, 42 of the last 112 days of pregnancy are more than seven days away from the last visit-that is, $38 \%$ so one would expect to find that $62 \%$ of these patients had been seen in the week before their eclamptic fit. In fact, $325(85 \%)$ had been seen This is despite a quarter of the patients having either no or less than standard antenatal care. Had these patients been brought back early because, at the previous visit, they had had hypertension or proteinuria or some other cause for concern? Antenatal care as described so dramatically in the classic paper by Hamlin remains the cornerstone of prevention of eclampsia. ${ }^{2}$ Altogether $89 \%$ of these patients had warning signs. We desperately need a test for "dangerous" toxaemia.

Finally, was there any difference in postpartum eclampsia between vaginal delivery and caesarean section? Probably none of the women who had a caesarean section would have been given ergometrine, and they would have been the more severe cases. It would not surprise us, however, if the incidence of postpartum eclampsia was higher in patients who had few signs of toxaemia and had been given ergometrine.

D G DANIEL

Consultant obstetrician and gynaecologist R H GOLDING

Royal Gwent Hospital Consultant obstetrician and gynaecologist

Newport,

Gwent NP9 2UB

1 Douglas KA, Redman CWG. Eclampsia in the United Kingdom. $B M 7$ 1994;309:1395-400. (26 November.)

2 Hamlin RHJ. The prevention of eclampsia and pre-eclampsia. Lancet 1952;i:64-8.

\section{Better standards of care will reduce morbidity and mortality}

EDrToR,-Traditional teaching is that eclampsia reflects poor standards in obstetric practice, and K A Douglas and C W G Redman's paper provides further evidence of this. ${ }^{1}$ Of the 383 women with eclampsia, 294 were inpatients when eclampsia occurred and only 36 had no recorded hypertension or proteinuria in the week before the first fit.

Successive confidential inquiries into maternal mortality have highlighted the seriousness of this condition, identifying important substandard care in $88 \%$ of deaths. ${ }^{2}$ It is disappointing to learn that $23 \%$ of the women with eclampsia in this study had less than standard antenatal care and that biochemical tests were so poorly used: only $54 \%$ of the women had their plasma creatinine concentration measured and only $30 \%$ had their transaminase concentration measured. The most recent confidential inquiry noted that ergometrine had been given to five of 27 women dying of hypertension disorders of pregnancy. ${ }^{2}$ We would be interested to hear from the authors whether similar inappropriate use of ergometrine was an important factor in postpartum eclampsia in their study.

The authors found that in those women whose blood pressure was recorded within an hour of the onset of convulsions the mean diastolic pressure was $97 \mathrm{~mm} \mathrm{Hg}$. We wonder whether they found any difference in blood pressure between the women who had eclampsia antenatally and those 
who had it postnatally; we could find no references where this has been investigated previously.

The authors' analysis of risk factors highlights some common misconceptions: a quarter of all the women with eclampsia were parous, $18 \%$ of all the women with eclampsia were parous with no history of pre-eclampsia or eclampsia in previous pregnancies, and teenagers were at three times greater risk than older women. Overall, this paper is a sobering reminder of the vigilance required if we are to reduce further the morbidity and mortality from this relatively common condition.

EDWARD O'DONNELI Registrar in obstetrics DAVID SOMERSET Birmingham Maternity Hospital, Senior house officer in obstetric Birmingham B15 2TG

1 Douglas KA, Redman CWG. Eclampsia in the United Kingdom $B M F$ 1994;309:1395-400. (26 November.)

2 Department of Health, Welsh Office, Scottish Home and Health Department, Department of Health and Social Services Northern Ireland. Report on confidential enquiries into maternal deaths in the United Kingdom 1988-1990. London: HMSO, 1994.

\section{Authors' reply}

EDrToR,-D G Daniel and R H Golding ask for more information on the women with eclampsia. Altogether 198 women were reported but excluded (60 after talking to consultants and 138 after the case note review) because they did not meet the criteria for the study. Seventy three of these had pre-eclampsia but no seizure; 56 had uncomplicated epilepsy; 40 had simple faints, hypoglycaemic fits, or pseudoseizures; and 29 had seizures without an apparent cause but did not have signs of pre-eclampsia.

Eighty nine women had a fit while under community based care, and for 64 of these we had access to a complete record of the care. Of the 64 women, six had hypertension alone, 11 had proteinuria alone, and five had hypertension and proteinuria documented before the onset of seizures. Twenty six of the 64 had been seen in the week preceding the fit.

The 27 women with multiple pregnancy were significantly less likely to have antepartum seizures than those with singleton pregnancies (relative risk ( $95 \%$ confidence interval) $0.18(0.05$ to 0.69$)$ ), but there were no significant differences between the two groups in terms of the presence of prodromal signs or symptoms, the gestation at onset of seizures, the number of seizures, or the ensuing maternal morbidity or mortality.

National data on number of previous stillbirths and live births do not exist, so that accurate calculation of rate of eclampsia in primiparous compared with multiparous women cannot be calculated accurately. Seventy one (99\%) of the teenagers were primiparous compared with 215 $(69 \%)$ of the women aged 20 or more. Part of the increased risk associated with teenage pregnancy may therefore be due to primiparity.

Whether or not the multigravidas had new partners was not determined, but $26(27 \%)$ had a history of pre-eclampsia and one (1\%) had a history of eclampsia. Multiparous women were significantly more likely to report prodromal symptoms than primiparous women (relative risk
$1.31(1 \cdot 11$ to 1.53$))$, but there were no significant differences in outcome measures.

Daniel and Golding's analysis of antenatal care assumes that eclampsia was uniformly spread through the last 112 days of pregnancy. Seizures were more common in the last four weeks of pregnancy, when it is routine to see women weekly; this helps to explain the high proportion of women seen within seven days of their seizure. Other women may have been brought back early or sought medical advice about symptoms. Our data are not detailed enough to supply this information.

There were no significant differences in the presence of prodromal symptoms (relative risk $1.00(0.75$ to 1.33$))$ or signs $(1.08(1.0$ to 1.17$))$ between women who had postpartum eclampsia after caesarean section or vaginal delivery. We did not record whether ergometrine was used in the third stage of labour.

In answer to the questions raised by Edward O'Donnell and David Somerset, women with antepartum eclampsia had significantly higher systolic and diastolic blood pressures within one hour of the onset of seizures than those with postpartum seizures (table). This is consistent with the overall picture of antepartum eclampsia being a more severe condition.

KA DOUGLAS Visiting research fellow C W G REDMAN Professor of obstetric medicin

Nuffield Department of Obstetrics and Gynaecology,

John Radcliffe Hospital,

Oxford University,

Oxford OX3 9DU

\section{Treating leg cramp}

\section{Naftidrofuryl is a safe and effective alternative}

EDITOR,-As part of their meta-analysis of the efficacy of quinine in treating leg cramp Malcolm Man-Son-Hing and George Wells review the pharmacological alternatives to quinine for this painful condition. They fail to mention naftidrofuryl. In a double blind placebo controlled crossover study of cramp at rest we showed naftidrofuryl to produce both a significant reduction in the frequency of cramp and an increase in the number of days free of cramp. ${ }^{2}$ Man-SonHing and Wells point out the possible serious side effects of quinine, and we suggest that naftidrofuryl should be regarded as an alternative, potentially less hazardous treatment for cramp at rest.

We agree with Man-Son-Hing and Wells that the condition is extremely common; indeed, we have shown a prevalence of $37 \%$ in the elderly population overall. ${ }^{3}$ Such a high prevalence further emphasises the need to use treatment with a low profile of side effects.

$$
\text { MARTIN J CONNOLLY }
$$
Senior lecturer J B YOUNG

Department of Care of the Elderly, Consultant physician

St Luke's Hospital,

JR NAYLOR

Department of Geriatric Medicine, J R NAYLOR
Consultant physician Huddersfield National Health Service Trust, Huddersfield Royal Infirmary, Huddersfield HD3 3EA
Comparison of blood pressures in women with antepartum onset of seizures and women with intrapartum and postpartum onsets. Figures are means (SD)

\begin{tabular}{lrrr}
\hline & $\begin{array}{c}\text { Antepartum } \\
\text { onset } \\
(\mathrm{n}=147)\end{array}$ & $\begin{array}{c}\text { Intrapartum and } \\
\text { postpartum onsets } \\
(\mathrm{n}=236)\end{array}$ & \multicolumn{1}{c}{ Significance* } \\
\hline Last systolic pressure (taken within one hour of onset of seizures) $(\mathrm{mm} \mathrm{Hg})$ & $166(26 \cdot 2)$ & $156(21 \cdot 2)$ & $5 \cdot 67, \mathrm{P}=0 \cdot 017$ \\
Last diastolic pressure (taken within one hour of onset of seizures) $(\mathrm{mm} \mathrm{Hg})$ & $105(14 \cdot 2)$ & $94(14 \cdot 0)$ & $18 \cdot 05, \mathrm{P}<0 \cdot 001$ \\
Maximum recorded systolic pressure (mmHg) & $185(26 \cdot 0)$ & $179(20 \cdot 7)$ & $\begin{array}{r}4 \cdot 51, \mathrm{P}=0 \cdot 034 \\
\text { Maximum recorded diastolic pressure (mm Hg) }\end{array}$ \\
\hline
\end{tabular}

^Kruskal-Wallis $H$ test $(1 \mathrm{df})$.
1 Man-Son-Hing M, Wells G. Meta-analysis of efficacy of quinine for treatment of nocturnal leg cramps in elderly people. $B M Y$ 1995;310:13-7. (7 January.)

2 Young JB, Connolly MJ. Naftidrofuryl treatment for rest cramp. Postgrad Med f 1993;69:624-6.

3 Naylor JR, Young JB. A general population survey of rest cramps. Age Ageing 1994;23:418-20.

The trial of naftidrofuryl ${ }^{2}$ received support from Lipha Pharmaceuticals, which provided the active drug and placebos, randomisation envelopes, and trial booklets to monitor patients recruited to the trial.

\section{Study quoted had flawed design}

EDITOR,-In their meta-analysis of the efficacy of quinine for night cramps Malcolm Man-Son-Hing and George Wells analysed six trials that met strict criteria for design.' Included in these six trials is one carried out by one of us (NRD) in 1991 on patients from his practice and a practice in Southampton. ${ }^{2}$ It is surprising that the authors included the data from this trial, since it was stated clearly that the results showed that the design of the trial was invalid. As the table shows, there was a clear carryover effect: patients who received quinine first, followed by placebo, experienced more nights with cramp in the placebo period than did those who received the placebo first. The test for carry over is significant (Mann-Whitney $\mathrm{W}=247 \cdot 5, \mathrm{P}<0 \cdot 05)$.

Proportion of nights with cramp

\begin{tabular}{llcc}
\hline Treatment & $\begin{array}{c}\text { 1st Period } \\
(\mathrm{n}=750)\end{array}$ & $\begin{array}{c}\text { 2nd Period } \\
(\mathrm{n}=750)\end{array}$ & $\begin{array}{c}\text { Both periods } \\
(\mathrm{n}=1500)\end{array}$ \\
\hline Quinine & $203(27)$ & $104(14)$ & $300(20)$ \\
Placebo & $278(37)$ & $488(65)$ & $765(51)$ \\
\hline
\end{tabular}

Because of the carryover effect the only valid comparison was between the two treatments in the first period. The difference was not significant (Mann-Whitney $W=183, P=0 \cdot 37$ ). The use of the combined figures for both periods by the authors of the meta-analysis is therefore not legitimate. The results from this trial suggest that the withdrawal of quinine after four weeks' treatment tends to induce leg cramps. This effect is dificult to explain and has not been reported elsewhere.

N R DUNN

Poole,

General practitioner

Dorset BH18 8BQ

M CAMPBELL

Department of Medical Statistics,

Southampton General Hospital,

Southampton SO9 4XY

1 Man-Song-Hing M, Wells G. Meta-analysis of efficacy of quinine for treatment of nocturnal leg cramps in elderly people. $B M$ 1995;310:13-7. (7 January.)

2 Dunn NR. Effectiveness of quinine for night cramps. $\mathrm{Br} f \mathrm{Gen}$ Pract 1993;43:127-8.

\section{Protection afforded by cycle helmets}

EDITOR,-According to Richard Keatinge and Ruth Parry, we "defy engineering evidence [unspecified] in stating that cycle helmets reduce the risk of serious head injury in accidents involving motor vehicles." They take us to task for not having mentioned the paper of Spaite et al. ${ }^{2}$ We referred to this paper in our report in $1993,{ }^{3}$ which we referenced in the letter to which Keatinge and Parry are responding. ${ }^{4}$ Spaite et al found that injuries to the head and body were less severe in helmeted riders. Sex and age were separately associated with use of a helmet, severity of injury, and mortality. In these circumstances a more sophisticated analysis was warranted, and Spaite et als conclusion that helmet wearing was simply a 